\title{
Preparation and Characterization of ZnO Thin Films by Using Two Different Techniques
}

\author{
S.Sivapriya ${ }^{1}$, K.Balasubramanian ${ }^{1 *}$. \\ ${ }^{I}$ Department of Physics, The MDT Hindu College, Tirunelveli-627006
}

\begin{abstract}
The ZnO thin films were deposited on glass substrate by Chemical Bath Deposition (CBD) and Successive Ionic Layer Adsorption and Reaction (SILAR) method. The prepared thin films were characterized by $X$-Ray Diffraction analysis (XRD), Scanning Electron Microscope (SEM), Energy Dispersive X-ray Analysis (EDXA) and UV-VIS Spectrophotometer. The XRD analysis shows the prepared thin films are polycrystalline nature and the average grain size of the films were calculated by using Debye Sherrie's formula. The study of surface morphology revels that the deposited ZnO films has Nano rod in shape. EDAX spectrum indicates that the film consists of Zinc and oxygen. The prepared thin films exhibit high transparency in visible region and the optical band gap energy were calculated by using Tauc Plot. The prepared ZnOfilm by Chemical bath deposition has been used for transparent electrodes in optoelectronic devices such as solar cell.
\end{abstract}

Keywords: ZnO, Thin film, CBD and SILAR.

\section{Introduction}

Thin films of $\mathrm{ZnO}$ have attracted great attention for their applications in semiconductor devices. Semiconductor thin films are always important in materials science due to their outstanding electrical and optical properties, which are useful in various optoelectronic devices. $\mathrm{ZnO}$ is a wide band gap semiconductor material [1-3]. $\mathrm{ZnO}$ thin films are widely used as conductive and optical cover layers of large area solar cell [4]. ZnO thin films have been prepared by various chemical and physical deposition techniques [5-8]. The present work is focused on the comparative analysis on the properties of $\mathrm{ZnO}$ thin films deposited by CBD and by SILAR techniques. It is observed that the deposition methods play an important role on the quality and properties of the $\mathrm{ZnO}$ films obtained.

\section{Experimental details}

$\mathrm{ZnO}$ thin films were deposited on glass substrate by the CBD and SILAR method. In this experiment, $0.1 \mathrm{M}$ of Zinc Chloride was prepared and small drops of ammonia were added and stirred continuously using magnetic stirrer to obtained optimum $\mathrm{pH}$ of 10 formed Zinc ammonia complexes. For CBD method, the cleaned substrates were vertically suspended in the beaker and the Zinc ammonia complex solution was constantly stirred using magnetic stirrer in a water bath of constant temperature of $800 \mathrm{C}$. The deposition time was $1 \mathrm{hr} .30 \mathrm{mins}$. After that $\mathrm{ZnO}$ thin film deposited substrate were removed, rinsed with distilled water and left to dry. SILAR method is a two-step process involving subsequent immersion of cleaned substrate in cationic (Zinc ammonia complex)for 5mins at room temperature and anionic (near boiling DI water)for 3Secthen the substrate was hanged on in the air to drying for $50 \mathrm{~s} .100$ deposition cycles were made and then the deposited $\mathrm{ZnO}$ films were characterized.

\section{Results and Discussions}

The prepared $\mathrm{ZnO}$ thin films were subjected to $\mathrm{XRD}$ measurements using $\mathrm{CuK} \alpha$ radiation (Wavelength $\lambda=0.15406 \mathrm{~nm}$ ). The absorption spectra of the $\mathrm{ZnO}$ thin films were recorded using SHIMADZU spectrometer in the range of $200 \mathrm{~nm}-1100 \mathrm{~nm}$. The surface morphology of the films was observed using Scanning electron Microscope (ZEISS) equipped with energy dispersive X-ray analyzer. Fig.1 shows that the XRD pattern for the as-prepared $\mathrm{ZnO}$ thin films The diffraction patterns were matched with standrard JCPDS files which shows that theparticles presented in the film belongs to Hexagonal system for both CBD and SILAR coated ZnO.The hkl values were indexed.The average crystalline size of prepared $\mathrm{ZnO}$ thin film was calculated using DebyeScherer's equation. The crystalline size of prepared CBD - $\mathrm{ZnO}$ is $41 \mathrm{~nm}$ and SILAR - $\mathrm{ZnO}$ is $30 \mathrm{~nm}$. 


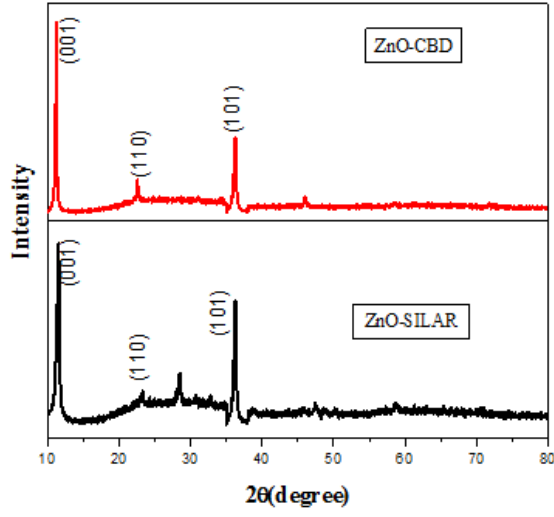

Fig.1 XRD Pattern for ZnO Films

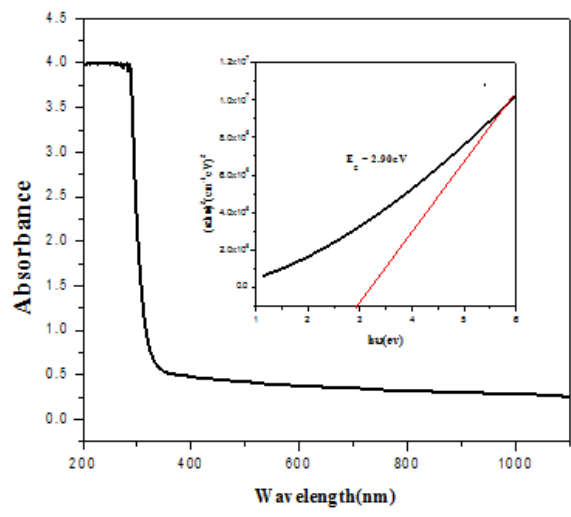

Fig.2 UV-Absorption spectrum of CBD-ZnO

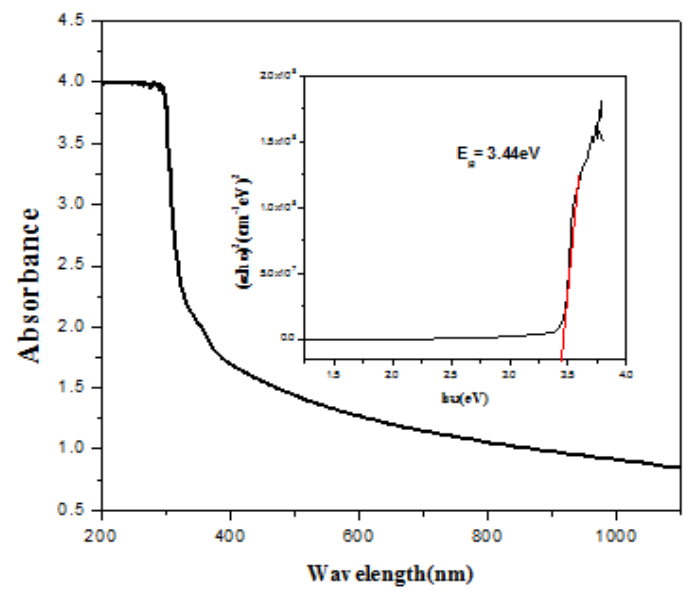

Fig.3 UV-Absorption spectrum of SILAR - ZnO

Fig.2 and Fig.3 shows the UV-absorption spectrum of CBD-ZnO and SILAR-ZnO thin films. The absorption spectra of prepared $\mathrm{ZnO}$ thin films exhibits strong absorption below 330nm which indicates that the film has wide transparency throughout the visible region, confirming the crystallinity of the $\mathrm{ZnO}$ thin films. From the UV- spectrum, the optical band gap energies of $\mathrm{ZnO}$ are determined by using tauc plot. The optical band gap values of CBD- $\mathrm{ZnO}$ and SILAR-ZnO is $2.90 \mathrm{eVand} 3.44 \mathrm{eV}$. The lower band gap value of CBD-ZnO is due to increased particle size with decreasing the surface area. This leads to high light harvesting efficiency in $\mathrm{CBD}$ coated $\mathrm{ZnO}$ when compared with SILAR coated $\mathrm{ZnO}$. Fig.4compares the surface morphologies of CBD (a) and SILAR (b) deposited $\mathrm{ZnO}$ thin films. The CBD deposited films have smalle nanorod shaped particles compared to the SILAR films. The Fig.5 shows that the EDAX spectrum of as prepared CBD and SILAR- ZnO thin films. The EDAX spectrum is consistent with the formation of $\mathrm{ZnO}$ on glass substrate.
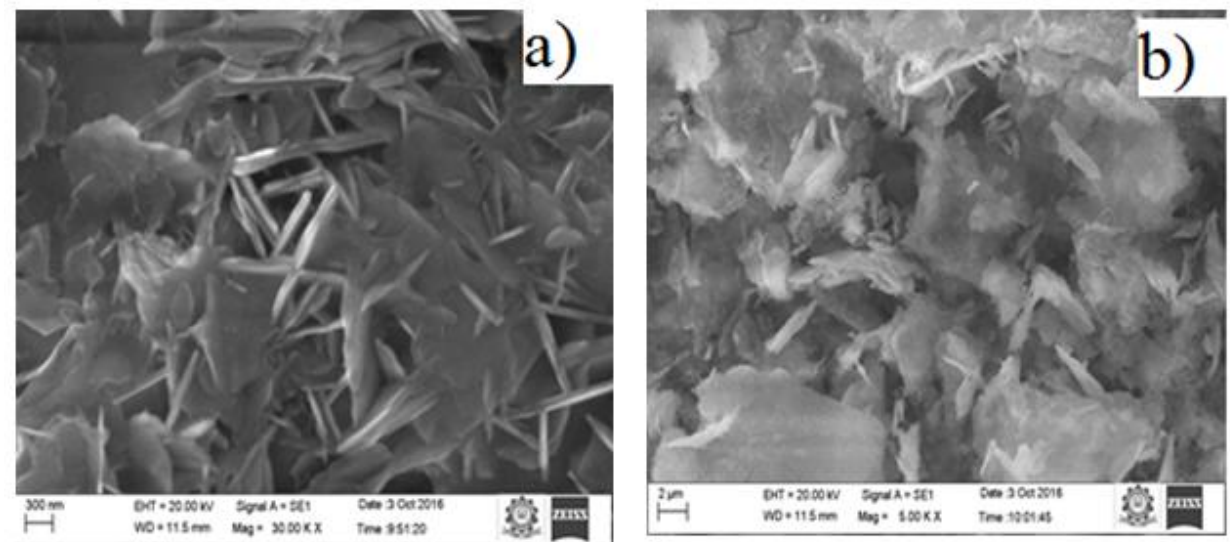

Fig.4 SEM image of CBD (a) and SILAR (b) deposited ZnO thin films.

National Conference on Current Advancements in Physics $3^{\text {rd }} \& 4^{\text {th }}$ February 2017 

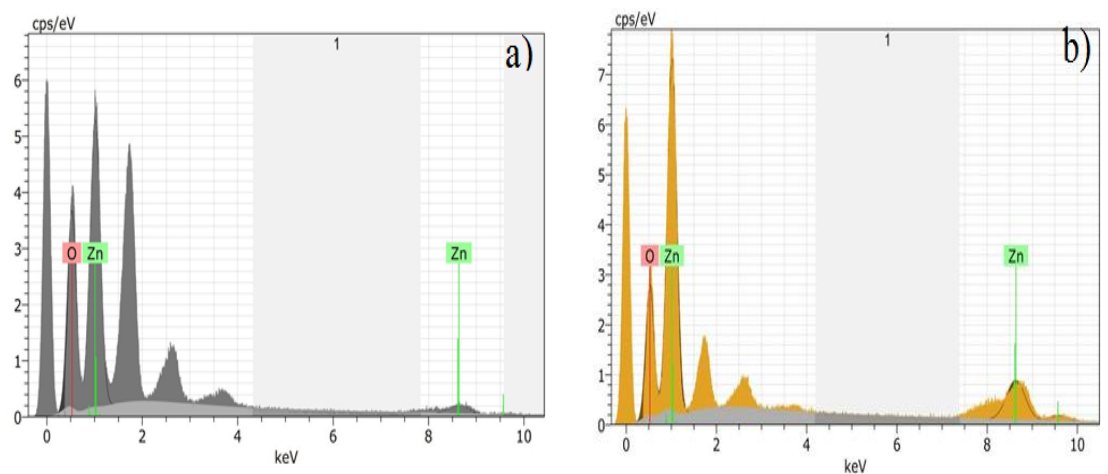

Fig.5 EDAX spectrum of $\mathrm{CBD}$ (a) and SILAR(b) deposited $\mathrm{ZnO}$ thin films

\section{Conclusions}

$\mathrm{ZnO}$ thin films were deposited on glass substrate by the CBD and SILAR method.XRD was carried out to find the crystal structure and particle size of the prepared thin films. From theoptical absorption spectrum the band gap values are calculated for CBD and SILAR coated $\mathrm{ZnO}$. The SEM image of $\mathrm{ZnO}$ thin films shows that the particles are nanorodin shape. EDAX spectrum shows that the formation of $\mathrm{ZnO}$ on glass substrate. Finally it was concluded tha CBD-ZnO has wide transparency which exhibit good ability to absorb sunlight compare with SILAR- $\mathrm{ZnO}$

\section{References}

[1]. J.C. Johnson, H. Yan, R. D. Schaller, L.H. Haber, R. J. Saykally and P. Yang, J.Phys. Chem.105, 11387 (2001).

[2]. Raidou, A., M. Aggour, A. Qachaou, L. Laanab, and M.Fahoume.M. J. Condensed Matter.12, 125, (2010)

[3]. T.O. Berestok, D.I. Kurbatov, N.M. Opanasyuk, A.D. Pogrebnjak, O.P. Manzhos, S.M. Danilchenko. journal of nanoand electronic physics, 5 , 01009, (2013)

[4]. D. Hariskos, S. Spiering, M. Powalla, Thin Solid Films, 99, 480 (2005).

[5]. Bernède, J. C., L. Cattin, M. Morsli, and Y.Berredjem. Solar Energy Materials and Solar Cells. 92, 1508, (2008).

[6]. M.H. Habibia, M.K. Sardashtia, J. Iran Chem. Soc., 5 603(2008).

[7]. H. Miyazaki, R. Mikami, A. Yamada, M. Konagai, Jpn. J. Appl. Phys., 45, 2618 (2006)

[8]. M. Ristov, G. J. Sinadinovski, I. Grozdanov and M. Mitreski, Thin Solid Films, 149, 65 (1987).

[9]. A. E. Jimenez-Gonzalez and P. K. Nair, "Photosensitive $\mathrm{ZnO}$ thin films prepared by the chemical deposition method SILAR", Semicond. Sci. Techol., 10, 1277 (1995). 